\title{
LA MUY DISCRECIONAL DOCTRINA DEL MARGEN DE APRECIACIÓN NACIONAL SEGÚN EL TRIBUNAL EUROPEO DE DERECHOS HUMANOS: SOBERANÍA E INTEGRACIÓN ${ }^{1}$
}

\author{
JAVIER GARCÍA ROCA \\ Catedrático de Derecho Constitucional \\ Universidad Complutense de Madrid
}

SUMARIO

I. Una cuestión previa: el falso dogma de la soberanía irrestricta como atributo del Estado.

II. Una constelación de principios formales para el enjuiciamiento de los litigios: proporcionalidad, necesidad de la medi$\mathrm{da}$, subsidiariedad y doctrina del margen de apreciación nacional

III. ¿Principio de integración funcional o margen de apreciación nacional?

IV. El banco de pruebas de la jurisprudencia. Algunos ejemplos del impreciso uso de esta doctrina.

V. Recapitulación.

1 El texto es una consecuencia de un estudio colectivo La Europa de los derechos: el Convenio Europeo de Derechos Humanos, J. García Roca y P. Santolaya (coordinadores), Centro de Estudios Políticos y Constitucionales, Madrid, 2005. Y se inserta en el Proyecto coordinado de Investigación, continuación del primero, que dirijo como investigador principal "La Europa de los derechos: objeto y contenidos de los derechos del Convenio a la Constitución Europea" (referencia SEJ2004-07631-C02-01/JURI), cofinanciado por el Ministerio de Ciencia y Tecnología y fondos FEDER de la Unión Europea. 
El llamado "margen de apreciación nacional" (en adelante, el margen) es una doctrina de consecuencias muy importantes y que ocupa un lugar central en la jurisprudencia de Estrasburgo, pero cuya aplicación práctica y construcción teórica tienen contornos altamente discrecionales e imprecisos $\mathrm{y}$, en consecuencia, no por ser una jurisprudencia necesaria, resulta menos controvertida. Mas no es nada fácil ofrecer por el momento soluciones alternativas.

\section{UNA CUESTIÓN PREVIA: EL FALSO DOGMA DE LA SOBERANÍA IRRESTRICTA COMO ATRIBUTO DEL ESTADO}

Un aparente obstáculo para admitir una revisión jurisdiccional plena, externa e internacional, de las decisiones de los Estados que han suscrito el Convenio Europeo de Derechos Humanos (desde ahora, CEDH o el Convenio) radicaría en un cierto entendimiento de la soberanía que podemos llamar absoluto; un rasgo formal que prácticamente nunca se ha plasmado en la realidad ni en la teoría y que, en la actualidad, no puede mantenerse jurídicamente dado los principios prescritos en la Carta de Naciones Unidas. La idea de soberanía "nacional" (en el sentido de "estatal" ${ }^{2}$ ) en todo caso subyace bajo el denominado "margen de apreciación nacional". Y, según se pretende por algunos Gobiernos demandados ante el Tribunal Europeo de Derechos Humanos (TEDH), esa comprensión absoluta de la misma permitiría eludir el control europeo en ciertos casos.

Para afrontar con rigor este dilema son necesarias algunas mínimas premisas teóricas acerca del alcance de la soberanía en el constitucionalismo y en el Derecho Internacional Público, aunque sólo pueda hacerse ahora un esbozo. La tesis que se refuta parte del error de creer que el poder soberano no admite límites: una "soberanía irrestricta" o "impermeabilidad a toda interferencia externa", constitutiva de una especie de "inmunidad" jurisdiccional ${ }^{3}$. Tal cosa no existe. Esa concepción incondicionada de la soberanía ni siquiera estaba en la construcción de Bodino ${ }^{4}$. La soberanía no es sólo un poder supremo, que no reconoce otro superior, es también «un recto gobierno no arbitrario", es decir, sometido a límites derivados, entre otras fuentes, de las leyes fundamentales del Reino en el siglo xvI; y, en nuestros días, de las Constituciones que disciplinan la forma de ejercicio del poder, así como de los trata-

2 Dada la identificación entre Nación y Estado que es habitual en Derecho Internacional, a diferencia de en Derecho Constitucional o en la teoría política. Y, claro está, tampoco se usa el término como en la génesis del constitucionalismo por el liberalismo desde su vieja contraposición con la soberanía "popular". Ni, por último, menos aún, desde la percepción común a las nacionalidades emergentes y la autodeterminación.

3 Bardo FASSBENDER: "Sovereignty and constitutionalism in Internacional Law" en Sovereignty in transition, edited by N. WALKER, Hart Publishing, Oxford-Portland, 2003, p. 117.

4 Juan BODINO: Los seis libros de la República, Aguilar, 1973, traducción y prólogo de Pedro Bravo, original en francés de 1576; se trata empero de una versión reducida. 
dos internacionales, libremente ratificados por los Estados, que restringen también su capacidad interna y soberana de decisión ${ }^{5}$.

Bajo el dogma de la soberanía se construyó el Estado absoluto y sobre él se asentó —como sabemos - el Estado liberal-nacional y después el Estado democrático; y la democracia constitucional que hoy gozamos se funda en la limitación de cualesquiera poderes. Pero los contextos son radicalmente distintos. Los derechos "humanos", y con más razón los que además gozan del rango constitucional de "fundamentales", son uno de los límites más importantes al ejercicio del poder. También el federalismo que articula una división territorial de poderes basada en la idea de "competencia" — que viene en parte a desplazar como categoría plenamente jurídica a la "soberanía" sobre todo en el ámbito interno- y se funda en la atribución diferenciada de potestades de distinta calidad a diversos entes. Y, desde luego, la integración europea que condiciona a los Estados constitucionales restringiendo sus facultades decisorias, y que igualmente supone una transferencia fragmentaria de soberanía y/o de competencia a una entidad supranacional; en realidad esto ocurre en general con todos los tratados, pero el fenómeno es mucho más intenso con los procesos de integración hasta suponer un salto cualitativo y alterar su misma esencia. Los derechos de los individuos sientan serias limitaciones a la soberanía tanto en su dimensión de "Soberanía interna", en las relaciones de los ciudadanos con su Estado, como en la de "Soberanía externa" o relaciones con la comunidad internacional".

El individuo tiene en la cultura del constitucionalismo un status, una posición constitucional, y también supranacional en el contexto del Consejo de Europa y del Convenio, como titular de derechos subjetivos incluso frente a su Estado al que puede demandar ante una jurisdicción exterior, si se considera víctima y en tanto en cuanto ese Estado la haya aceptado.

Decía Duguit tras la I Guerra Mundial, al analizar la soberanía nacional en el interior y la libertad del individuo lo siguiente. "La soberanía del Estado puede intervenir para limitar los derechos de cada uno, pero únicamente en la medida necesaria para proteger los derechos de todos y no puede hacerlo sino por una ley, una disposición general dictada por sus representantes", la soberanía encierra el poder de hacer las leyes, sin embargo este poder tiene un límite en los derechos naturales del hombre a los cuales no puede atentar?

5 Es no menos clásico como descripción del proceso Georg JELLINEK: Teoría General del Estado, Albatros, Buenos Aires, traducción y prólogo de Fernando de los Ríos,1978, capítulo catorce "Las propiedades del poder del Estado". La primera edición en alemán es de 1900. La traducción del catedrático de la Universidad de Granada apareció en 1913, de ahí su temprana y larga influencia en España.

6 Entre otros, Pablo LUCAS VERDÚ: Curso de Derecho Político, vol. II, "El poder político soberano", pp. 108-125, Tecnos, Madrid, 1974. Más reciente, Vlad CONTASTINESCO y Stéphane PIERRÉ-CAPS: Droit Constitutionnel, Thémis, Presses Universitaires de France, 2004, "La genèse de la notion de souveraineté", pp. 10-20. Es clásico, Hermann HELLER: La soberanía (Contribución a la teoría del derecho estatal y del derecho internacional), Fondo de Cultura Económica, México, 1995, 2. ${ }^{a}$ ed, traducción de Mario de la Cueva, original de 1927.

7 Leon DUGUIT: Soberania y libertad (Lecciones dadas en la Universidad de Columbia), traducción y prólogo de José G. Acuña, Beltrán, Madrid, 1924, original de 1921, p. 207. 
"La autonomía del individuo es anterior y superior a la soberanía de la Nación a la que viene a limitar" ${ }^{8}$. El Estado constitucional debe adecuar su organización y el uso de sus potestades a la libertad. Y los derechos reconocidos internacionalmente son, por tanto, un límite indudable a la soberanía y deberíamos tomarnos seriamente este aserto.

Desde el punto de vista de una comunidad internacional fundada en las ideas de "cooperación", y, en particular, en Europa (pero también en Iberoamérica $^{10}$ ), de "integración", tanto en el contexto de la Unión Europea como en el más amplio del Consejo de Europa, transferir la competencia para juzgar —reconocer «jurisdicción»- a un Tribunal Internacional no sólo para enjuiciar concretas violaciones de derechos sino para algo más ambicioso, protegerlos de forma efectiva y colectiva (collective enforcement) en aras a una integración común, es un fenómeno que se asemeja a la transferencia parcial de una de las marcas sensibles de soberanía de las que hablaba Bodino. Del mismo modo que acontece con la vieja competencia para acuñar moneda hoy en manos de la Unión Europea en la zona euro.

Me parece, en definitiva, que la tutela judicial de los derechos humanos y su garantía colectiva acaban, en definitiva, por transformar la naturaleza de una protección estrictamente internacional. Pero debemos ser prudentes, sólo en parte es así. Duguit daba ingenuamente por muerta, en su viaje a los Estados Unidos, la soberanía de las viejas Naciones tras vivir los horrores de la I Guerra Mundial en Europa ${ }^{11}$. Pero sigue viva y coleando, según demuestran los problemas internos para la ratificación por algunos Estados del tratado constitucional para Europa, por más que ahora en transición. Y no es preciso recordar todas las atrocidades que hemos contemplado después...

\section{UN CONSTELACIÓN DE PRINCIPIOS FORMALES PARA EL ENJUICIAMIENTO DE LOS LITIGIOS: PROPORCIONALIDAD, NECESIDAD DE LA MEDIDA, SUBSIDIARIEDAD Y DOCTRINA DEL MARGEN DE APRECIACIÓN NACIONAL}

Con los enunciados en el epígrafe, las normas que reconocen derechos en el "sistema del Convenio" y otros ingredientes el Tribunal Europeo construye un parámetro y unas reglas y principios de referencia para enjuiciar las vio-

8 Idem, p. 59.

9 Cfr Bardo FASSBENDER: op. cit., epígrafe "Sovereignty in the International Law of coexistence", quien concluye que la cooperación bajo el paraguas de las organizaciones supranacionales sustituye a la soberanía nacional como el tema central de las relaciones internacionales, p. 120.

$10 \mathrm{La}$ problemática es en esencia semejante en el ámbito de la Convención Americana de Derechos Humanos según expone Nestor P. SAGÜES: "Las relaciones entre los Tribunales internacionales y los Tribunales nacionales en materia de derechos humanos. Experiencias en Latinoamérica" en Ius et Praxis. Derecho en la región, Universidad de Talca, Facultad de Ciencias Sociales y Jurídicas, año 9, núm. 1, pp. 4-20.

11 Leon DUGUIT: quinta lección, pp. 130 y ss. 
laciones de derechos. Pero, con demasiada frecuencia, se entremezclan cosas diversas que convendría diseccionar de manera analítica:

- La "necesidad de la medida" en una sociedad democrática, conforme al apartado 2. ${ }^{\circ}$ de los artículos 8 a $11 \mathrm{CEDH}$, es parte del habitual juicio de proporcionalidad que hace Estrasburgo y puede incluirse dentro del denominado "subprincipio de necesidad" ${ }^{12}$.

- El propio margen de apreciación nacional - estimo- es un ingrediente más de ese juicio de proporcionalidad. Un límite estructural a su aplicación que permite no entrar a revisar en ciertos casos la interferencia en el derecho si el fin de la restricción es legítimo, y la medida y la regulación son necesarias a ojos de las autoridades nacionales y todo ello no resulta irrazonable a la Corte. El margen puede pues esgrimirse, bien a instancia de parte o de oficio, para reducir el alcance del control europeo en provecho de la decisión de las autoridades nacionales.

- Un principio de subsidiariedad que se manifiesta en ese margen y es una de sus consecuencias, pero cuyos contenidos son más amplios.

La doctrina del margen no está incluida de forma expresa entre los preceptos del Convenio Europeo ni tampoco fue mencionada ni debatida en los trabajos preparatorios ${ }^{13}$. Un dato que merece la pena reservar. Pero es inmanente a la lógica de la subsidiariedad ${ }^{14}$, que es inherente a una protección internacional y debe lógicamente producirse después de la interna y en defecto de la misma. La justificación de esta doctrina procede de la misma naturaleza de una tutela internacional.

Su origen es oscuro. Se ha dicho que parece proceder de las técnicas de la revisión judicial propias de los Estados, en particular, del Consejo de Estado francés ${ }^{15}$. Pero ha sido la Corte de Estrasburgo la que ha desarrollado la idea con perfiles propios. Es más exacto decir que "los órganos de Estrasburgo". Pues la Comisión la usó primero en tempranos casos como el de la denuncia del Reino Unido a Grecia, por implantar medidas de emergencia en

12 Cfr Carlos BERNAL: El principio de proporcionalidad y los derechos fundamentales, Centro de Estudios Políticos y Constitucionales, Madrid, 2003, prólogo de J.L. Cascajo, pp. 734-757.

13 Howard Charles YOUROV: The margin of appreciaton doctrine in the dynamics of European Human Rights jurisprudente, Kluwer Law International, La Haya/ Boston/ Londres, 1996, p. 14.

14 Entre otros muchos, Diana-Urania GALETTA: "Il principio de proporzionalità nella Convenzione Europea dei Diritti dell'Uomo, fra principio di necessarietà e doctrina del margine di apprezzamento statale: riflessioni generali su contenuti e rilevanza effettiva del principio" en Rivista Italiana di Diritto Pubblico Comunitario, 1999, núm. 3-4, p. 748.

15 Vid Ronald St John MACDONALD: "The margin of appreciation in the jurisprudence of the European Court of Human Rights" en Il Diritto Internazionale al tempo della sua codificazione. Studi in bonore di Roberto Ago, Giuffrè, Milán, 1987, pp. 187-208, epígrafe "Origin and history of the margin of appreciation", pp. 187 y ss; también Howard Charles YOUROV: op. cit., "Birth of the margin doctrine", pp. $15 \mathrm{y}$ ss. 
Chipre, y otros ligados al art. $15 \mathrm{CEDH}^{16}$ (el siguiente fue el no menos conocido Caso Lawless), que permite derogar las obligaciones del Convenio en casos de guerra o de peligros públicos en la medida estricta en que lo exija la situación. En ese contexto, el margen estaba ligado a una lógica discrecionalidad del Estado a la hora de valorar las exigencias de una situación de emergencia, que limitaba la intensidad de la supervisión de la Comisión cuando valorase las medidas adoptadas ${ }^{17}$. Un origen trágico o, cuando menos, dramático: una situación de emergencia y de suspensión de derechos. Quizá de esta brusca procedencia derive su cierta tosquedad o elementalidad. La jurisdicción europea no había alcanzado todavía la sofisticación actual. Mas puede que no sea cabal utilizar como instrumento de control ordinario una herramienta surgida en supuestos de hecho tan drásticos. Hace falta un instrumento más complejo y normalizado para una revisión ordinaria de los derechos.

La descripción que la Corte efectúa del margen estimo que puede considerarse como una construcción débil ${ }^{18}$ en cuanto poco densa y susceptible de aplicaciones muy variadas si no contradictorias. Suele decir que "la maquinaria de protección establecida por el Convenio es subsidiaria de los sistemas nacionales de garantía de los derechos humanos" (Casos Handyside, de 7 de diciembre de 1976, y Sunday Times, de 26 de abril de 1979, ambos contra el Reino Unido), que el legislador dispone de un gran espacio para establecer y mantener direcciones políticas propias a través de las leyes, y que una Corte supranacional debe respetar estas orientaciones "salvo si el juicio se revela manifiestamente desprovisto de bases racionales". Pero más allá de esta descripción, que refleja un fenómeno indiscutible, no es fácil encontrar en la jurisprudencia una caracterización más precisa. La idea básica es pues que los Estados partes tienen un cierto margen de discrecionalidad en la aplicación y el cumplimiento de las obligaciones impuestas por el Convenio y en la ponderación de intereses complejos. No obstante, si en el uso de esa discrecionalidad que el margen permite, el Estado se sobrepasa y se produce un exceso, un ultra vires, aunque parezca en sí mismo legítimo, la lógica del respeto al principio de proporcionalidad aboca a una supervisión europea ${ }^{19}$.

Con el mecanismo de la subsidiariedad la Corte y los Estados miembros se aseguran la conjunción entre los niveles nacional e internacional ${ }^{20}$. Se sienta como regla que la víctima debe intentar un previo agotamiento de los recursos internos y, a la par, se reconoce que la Corte, en estricta aplicación

16 Cfr idem, p. 188; Howard Charles YOUROV: op. cit., epígrafe "Leading cases to 1979: toward standards", pp. 25-54.

17 Véase Oren GROSS \& Fionnuala NÍ ALOÁIN: "From discretion to scrutiny: revisiting the application of the margin of appreciation doctrine in the context of article 15 of the European Convention on Human Rights" en Human Rights Quarterly, núm. 23, 2001, p. 626.

18 Puede verse Ronald St John MACDONALD: op. cit., pp. 192 y ss., "The meaning of...".

19 Así se dice expresamente v.gr. en el Caso Fedorenko contra Ucrania, de 1 de junio de 2006, $₫ 356$.

20 Diana-Urania GALETTA: op. cit., p. 747. 
del Convenio, concede el primer lugar a los Estados miembros en la garantía de los derechos. Pero, si la satisfacción no se produjera por las autoridades nacionales (primer supuesto, la consagración de la lesión), o si la reparación obtenida se revelara inidónea para una protección adecuada del derecho supuestamente violado (segundo supuesto, una reparación insatisfactoria), entonces la Corte puede revisar la decisión nacional y sustituirla por otra más adecuada al Convenio. La Corte no debe en cualquier caso intervenir si el Estado miembro asegura una protección mejor o cuando menos equivalente. La afirmación es importante porque una de las conclusiones principales de la investigación colectiva que dirigimos sobre el Convenio ${ }^{21}$ es que normalmente la protección española de los derechos es más elevada que la común que nos dispensa el Consejo de Europa, aunque no hubiera podido crearse sin ella, y por consiguiente, cuando así sea, no debe ser desplazada.

La subsidiariedad comporta dos notas que, una vez que uno profundiza en el asunto, parecen encontrase en cierta insoslayable tensión:

- Carácter final: el TEDH es infalible porque es final. Sus sentencias no son apelables. Después de Estrasburgo el recurrente no puede ir a ninguna otra sede jurisdiccional (dejemos por ahora a un lado el Consejo de Derechos Humanos de Naciones Unidas).

- Un limitado poder de sustitución: una facultad de revocación de una decisión de las autoridades nacionales limitada precisamente por tratarse de una protección internacional.

Y, entre otras manifestaciones en el Convenio de esa subsidiariedad ${ }^{22}$, están las siguientes:

- Ya que al TEDH no puede acudirse sino después de agotar las vías de recurso internas (art. 35.1 CEDH), los Estados tienen una obligación positiva de prever un sistema de recursos, y el Tribunal puede condenarlos si incumplen esa obligación (todavía con alguna frecuencia ocurre). La disparidad de los sistemas jurídicos de los 46 Estados inevitablemente ofrece soluciones procesales muy diversas que no parece puedan ni deban armonizarse.

- En el momento de la firma del Convenio, los Estados pueden hacer reservas o declaraciones, manifestar sus reparos o cautelas, respecto del sentido de alguna disposición o frenar alguna de sus interpretaciones (art. $57 \mathrm{CEDH}$ ). Pero, pasado un tiempo prudencial a fin de que el Estado parte se asiente en el sistema del convenio, algunas de estas reservas y las cautelas a la ratificación de nuevos protocolos suelen perder buena parte de su sentido inicial —esa al menos ha sido la experiencia española-.

21 Cfr Javier GARCÍA ROCA y Pablo SANTOLAYA: La Europa de los derechos: el Convenio Europeo de Derechos Humanos, op. cit.

22 Véase Diana-Urania GALETTA: op. cit., p. 748. 
- Respecto de las restricciones de derechos, los límites impuestos por el Convenio no se pueden aplicar más que con la finalidad con que han sido previstos (art. 18). Quien tiene que "delimitar" o en su caso "limitar" - lo que no es exactamente lo mismo como ha precisado bien Häberle ${ }^{23}$ - en primer lugar los derechos son los Estados miembros mediante sus propias leyes, justamente por poseer una legitimidad democrática y la confianza de sus ciudadanos.

En definitiva, el margen de apreciación nacional entraña tanto una cierta discrecionalidad de los Estados como una regla de decisión o, mejor aún, de no decisión que no es sino la otra cara de la misma moneda: el Tribunal Europeo puede no enjuiciar el asunto y ratificar la decisión nacional. Según tal doctrina, la Corte debe autolimitarse si la solución adoptada tiene la razonable apariencia del buen Derecho en vez de sustituir al Estado demandado con sus propios puntos de vista.

Mahorney afirma que es necesario un instrumento interpretativo, cual es el margen, que trace una línea divisoria entre las cuestiones que debe decidir cada comunidad nacional y las que tienen suficiente relevancia o fundamentalidad como para necesitar una solución homogénea ${ }^{24}$; aquéllas que demandan una decisión que armonice la regulación del derecho y sus garantías en la comunidad internacional con independencia de las diferencias en tradición y cultura. Una especie de regla de división de jurisdicciones. Pero se antoja una diferencia de grado, más de cuantía que de cualidad: ¿qué es fundamental o principal en un derecho y qué accidental? De ahí la dificultad de hacer un juicio jurídico y el riesgo de consagrar una excepción política basada en esta pauta hermenéutica que es el margen. Mientras el TEDH no resuelva de forma previa, abstracta y general, - y no lo ha hecho ni es fácil hacerlo- que es fundamental y común en cada uno de los derechos, el juicio seguirá siendo muy impreciso.

En definitiva, la doctrina del margen de apreciación nacional produce una tremenda discrecionalidad de la Corte ${ }^{25}$. Tenemos una frontera entre las jurisdicciones nacionales y europea de derechos, pero es una delgada línea en

23 Peter HÄBERLE: La garantía del contenido esencial de los derechos fundamentales, Dykinson, Madrid, 2003, traducción de Joaquín Brage, original en alemán de 1962, la incorpora a la teoría de los derechos. Sin embargo, la distinción entre "límite" o confín de los derechos y las "limitaciones" es anterior, y estaba ya en la doctrina iuspublicista sobre la propiedad privada, su función social y la expropiación forzosa, y en la misma idea, aún más vieja, de "servidumbre".

24 Vid Paul MAHORNEY: "Marvellous richness diversity or individual cultural relativism" en Human Rights Law Journal vol. 19 núm. 1, 30 de abril de 1998, p. 1, monográfico "The doctrine of the margin of appreciation doctrine under the European Convention on Human Rights: its legitimacy in theory and application in practice". Allí mismo Jeroen SCHOEKKENBROEK: "The basis, nature and application of the margin of appreciation doctrine in the case law of the European Court of Human Rights", pp. 30-36.

25 Cfr Steven GREER: The margin of appreciation: interpretation and discretion under the European Convention on Human Rights, Council of Europe Publishing, Estrasburgo, 2000. 
el horizonte que no se sabe muy bien por donde discurre. Pero no nos asustemos, estamos muy acostumbrados a que esto ocurra en Europa ${ }^{26}$ y en ámbitos más delicados...

No es raro pues que todos los autores coincidan en que el margen es un instrumento impreciso, diríase que de geometría variable ${ }^{27}$, lo que es grave porque se superpone a la misma relativa indeterminación de los derechos; sin embargo, discrepan sobre su necesidad. La doctrina mayoritaria reconoce, no obstante, el rol esencial de esta doctrina que juega un papel, hoy por hoy, inevitable. Y matiza que no es una "carta blanca" a los Estados ${ }^{28}$ para hacer lo que quieran con los derechos de sus justiciables. Ahora bien — a mi juicio—, la herramienta requiere de una depuración teórica que permita una aplicación más precisa.

Su uso supone una autocontención (self-restraint) por parte de la Corte que, por definición, no debe normalmente sustituir las apreciaciones de las autoridades nacionales sobre la prueba de los hechos, la interpretación de la legalidad ordinaria o la configuración por el legislador de los derechos en cada ordenamiento. La Corte suele comenzar sus sentencias identificando y recordando las normas internas antes de hacer lo mismo con las internacionales. Y el Convenio Europeo no es un texto refundido que reclame la adopción de las mismas decisiones por parte de todos los Estados miembros antes bien supone singularizar unos estándares mínimos comunes. El nivel de protección de los derechos y las diversas fórmulas o variantes posibles para concretarlos distan todavía de ser homogéneos en naciones con tradiciones jurídicas y culturales tan diversas. Pero nadie se limita bien a sí mismo si no se ha asentado una división de poderes, tampoco los tribunales. Esa es mi experiencia como Letrado al servicio del Tribunal Constitucional español y como constitucionalista: está en la condición humana y de cualquier poder que el titular de un órgano no sometido a contrapesos por otro se desborde...

Entre los elementos que articulan esta regla de decisión según la jurisprudencia europea — parto de la identificación que hizo Mahorney ${ }^{29}$ - podemos señalar los siguientes:

- La existencia de una base normativa común. Una misma regulación de la institución controvertida en la mayoría de los Estado miembros. Un

26 También en Iberoamérica parece haberse adoptado la doctrina del "seguimiento nacional". Cfr Nestor P. SAGÜES: op. cit., por ejemplo, la Corte Suprema de Justicia de Argentina en los casos Ekmekdjian, Giroldi y Bramado para puntualizar que la interpretación de los derechos humanos que haga la Corte Interamericana debe servir de guía a los tribunales argentinos. pp. 10 y ss. Por el contrario, otros tribunales, como el Consejo Superior de Justicia Militar del Perú, caso Castrillo Petruzzi, dictaron una improcedente "declaración de inejecutabilidad", adoptando un escenario más conflictivo y sin salida, p. 6 y ss. A su juicio, entre uno y otro camino, y con el afán de compatibilizar las jurisdicciones nacionales e internacionales de derechos, podría situarse la doctrina del "margen de apreciación nacional", pp. 13 y ss.

27 Diana-Urania GALETTA: op. cit., p. 750.

28 Paul MAHORNEY: op, cit., p. 6. p. 751

29 Paul MAHORNEY: op, cit., 1998, p. 5. Más tarde Diana-Urania GALETTA: op. cit., 1999, 
argumento que, tras identificar un mínimo denominador común, permite adoptar una solución compartida. Este método obliga a la Corte a hacer una indagación de Derecho comparado acerca de la legislación vigente en los diversos ordenamientos estatales. Y, claro está, constatada la falta de un consenso normativo europeo, la situación autoriza o, cuando menos, refuerza la posibilidad de un margen de apreciación nacional.

- La naturaleza del derecho es un ingrediente central del cual me ocuparé especialmente más adelante.

- La naturaleza del deber del Estado como sujeto pasivo de obligaciones internacionales o el tipo de actuación que se reclama al Estado demandado: simplemente abstenerse de actuar o una obligación positiva de actuación.

- La naturaleza del fin perseguido por la interferencia nacional en el derecho o de la medida que articula esa interferencia.

- La naturaleza del objeto de la regulación legal interna sobre la que se proyecta el derecho humano.

- La existencia de circunstancias particulares como pueden ser una situación de emergencia o de peligro (recuérdese que la doctrina nace ligada al art. $15 \mathrm{CEDH}$ ), o la especial susceptibilidad o sensibilidad nacional en la materia: al cabo las diferentes realidades sociales sobre las que las normas convencionales vayan a ser aplicadas ${ }^{30}$.

- Y, desde luego, los límites y previsiones expresas del Convenio.

El TEDH usa habitualmente estos ingredientes, pero no los ha sistematizado. La crítica que fácilmente aflora es ésta ¿cómo se pueden ponderar media docena de criterios tan dispares entre sî? ¿Cuál debemos elegir en cada caso? Parece que estamos ante una simple commixtio y no ante un verdadero criterio de interpretación jurídica de una declaración internacional de derechos. No se puede fundar algo que se pretende sea una doctrina en tantos criterios que son además contradictorios entre sí. Ningún verdadero concepto o categoría jurídica es susceptible de ser manejado con tan variados criterios en vez de uno sólo. ¿Es el margen sólo una cláusula de estilo? O refleja una realidad tozuda e inaplazable y, si no existiera esta doctrina, debería inventarse.

Cabe asimismo pensar que hay alguna similitud entre la doctrina del margen y las "political questions" ante las jurisdicciones constitucionales que pronto decantó en su jurisprudencia la Corte Suprema de los Estados Unidos

30 Como muestras de esas diferentes realidades sociales ponderadas por el TEDH podemos mencionar v.gr. la importancia del principio de laicidad en la idea de republicanismo y en la unidad nacional en Turquía, un país seriamente amenazado por el fundamentalismo islámico, me refiero al Caso del Refah Partisi al que aludiré más adelante. O la inconveniencia de hacer propaganda religiosa mediante la radiodifusión en el ejercicio de la libertad de expresión en sociedades sensibles como ocurre con Irlanda del Norte, vistos los enfrentamientos entre católicos y protestantes, según el Caso Murphy contra Irlanda, de 10 de julio de 2003. 
para rehuir juzgar ciertos asuntos al estimarlos no justiciables v.gr. las Constituciones de los Estados o las enmiendas constitucionales federales. Una posición inicial que ella misma ha ido limitando ${ }^{31}$. Del mismo modo, cabria pensar que, aunque la Corte Europea reconozca un cierto margen a los Estados, nunca podrá ser absoluto, pues violaría la lógica de la proporcionalidad y del justo equilibrio de intereses que habitualmente preserva, $\mathrm{y}$, por consiguiente incluso algunos de los elementos prima facie amparados por ese margen podrían ser revisados si se produce un exceso que deba ser corregido. Al igual que en los actos políticos existen siempre elementos reglados y plenamente revisables según la doctrina científica y jurisprudencial más moderna que se ocupa de los mismos. La doctrina del margen no puede autorizar un tipo de actos en sí mismos y en todos sus elementos y consecuencias posteriores irrevisables si no quiere asumirse el riesgo inaceptable de consagrar situaciones materiales de indefensión; un escenario que pugna con la razón inherente a todo verdadero Derecho. Así los Estados v.gr. podrán sin duda gozar de un margen para regular como deseen la investigación de la paternidad o la recopilación de información política por los servicios secretos de inteligencia, pero las aplicaciones arbitrarias o excesivas de estas normativas, contrarias al Convenio en alguno de sus elementos o en una consideración de conjunto, deben estar sujetas a la revisión del TEDH, quien así lo ha hecho en ambos ejemplos.

Por último, el juego de esta doctrina no es el mismo en los distintos derechos: depende de su naturaleza. Me parece que éste es el ingrediente esencial de todos los que se han enunciado anteriormente. Usando la habitual imagen de tres círculos concéntricos podríamos decir que:

- Hay veces que el margen de apreciación nacional que concede la Corte es amplio y el control europeo poco intenso. Así ocurre en un círculo externo v. gr. integrado por los derechos de propiedad en cuanto derechos aparentemente con escaso contenido esencial y una intensa configuración legal; y también con las diversas especies del derecho a un proceso equitativo muy abiertas a su configuración legal en los procesos.

- En un círculo interno y más pequeño, estarían situados derechos absolutos como la vida o los tratos prohibidos por el Convenio (artículos $2 \mathrm{y}$ 3) o los derechos democráticos - la democracia es un elemento fundamental e indefectible del orden público europeo- donde el control es estricto y el margen de apreciación nacional pequeño.

- Y, en un muy amplio círculo intermedio, situaríamos el resto de derechos. Es justo ahí donde la doctrina científica debe concentrarse en construir criterios más precisos y modernos.

31 Más en general, esta cuestión evoca el alcance de la justicia constitucional en todos aquellos supuestos en los que se trata de decidir sobre extremos de fondo respecto de los que la Constitución no se pronuncia y deja al legislador, dentro de un margen que ella predetermina, su precisión. 
Esta triple distinción puede efectuarse en teoría, como una primera aproximación y con afán de desbrozar los aspectos lógicos del problema, pero, en la práctica, hay situaciones dentro de ese círculo externo, propio de un control poco intenso, en que, por el contrario, la Corte revisa muchos extremos de detalle. Una situación contradictoria que acaba por complicar la construcción teórica de la doctrina jurisprudencial. Tengo recopilados bastantes casos, v.gr. respecto de los derechos de propiedad, en los que el Tribunal se adentra a precisar extremos minuciosos referidos a los bienes que pueden ser objeto del derecho o su propia configuración legal. A veces incluso el TEDH reconoce que el margen nacional es amplio, para a continuación estimar que la regulación estatal viola el Convenio. Un amplio margen nacional en teoría, pero, en algunos casos, compatible con un control europeo en la práctica bastante intenso. El binomio entre la amplitud del margen nacional y la supuestamente inversa intensidad del control europeo no siempre está en una relación lineal. O podríamos decir que la teoría del margen discurre a veces por un lado y la realidad de la jurisprudencia por otro.

Quizá podamos continuar la reflexión partiendo del lugar de ubicación del Juez: lo que llamaré la paradoja sobre la sede de enjuiciamiento. La Corte Europea a veces estima que, estando los Estados en contacto directo y continuo con la realidad de cada país, se encuentran en una mejor posición para ponderar los intereses en conflicto. Diríase que la nacional parece ser mejor sede para un juicio concreto, que es el típico de las colisiones de derechos, a diferencia del control de constitucionalidad, directo y abstracto, de las leyes. Pero una decisión sobre la ubicación del juez no siempre será tan sencilla como ilustra, entre otros, el complejo Caso del Partido de la Prosperidad (Refah Partisi) contra Turquía, de 31 de julio de $2001^{32}$. ¿Dónde se advierte mejor la entidad de las actividades antidemocráticas de un partido político hasta el punto que justifique su disolución en Ankara o en Estrasburgo? ¿Es mejor que el observador se situé en la orilla o nadando esforzadamente en el agua? ¿Qué perspectiva es mejor: la próxima y nacional o la distante y europea? Un viejo problema de toda filosofía. Cómo alcanzar a la vez un distanciamiento de los hechos y un adecuado conocimiento de las complejas realidades nacionales. A menudo no se pueden tener ambas cosas, las dos perspectivas son incompatibles y habrá que elegir según los casos. Tomemos el asunto Bultó (Caso Barberá, Messeguer y Jabardo contra España, de 6 de diciembre de 1998) podíamos verdaderamente los españoles distanciarnos suficientemente como para apreciar ciertas minuciosas lesiones de las garantías procesales de los terroristas después del terrible dolor que su violencia había inflingido a nuestra comunidad durante lustros... La distancia permite la serenidad del espíritu pro-

32 Vid Javier GARCÍA ROCA: "La problemática disolución del Partido de la Prosperidad ante el Tribunal Europeo de Derechos Humanos: Estado constitucional y control de las actuaciones de partidos fundamentalistas" en Revista Española de Derecho Constitucional, núm. 65, 2002, pp. 295334. Una sentencia aprobada por estrecha mayoría y confirmada por una Gran Sala el 13 de febrero de 2003 . 
pia del juzgador imparcial. Pero un juicio sabio y constitucionalmente adecuado demanda conocer la realidad fáctica y normativa que se juzga y ello exige proximidad e inmediatez y conocimiento del Derecho nacional. Por eso estimo imprescindible, como complemento, un subsidiario, lejano e independiente control europeo. Pero no es sencillo resolver cuándo esa supervisión no debe sustituir y desplazar a la estatal. En todo caso, obsérvese que el juicio europeo acaba realizándose después del nacional, una vez que la ponderación de los hechos y la interpretación de legalidad ya ha sido realizada, y consta en las actuaciones del procedimiento y debe normalmente respetarse de no existir una arbitrariedad.

Por otro lado, la doctrina del margen expresa bien el actual punto equidistante entre el originario Derecho Internacional, del que emana el tratado, y la progresiva garantía constitucional judicializada que entraña el Convenio. Un instrumento del orden constitucional europeo desarrollado cada vez más con principios y criterios propios de una interpretación constitucional en vez de únicamente con los tradicionales principios del Convenio de Viena sobre los tratados, pero que dista todavía de ser una declaración constitucional por su supremacía formal y material ${ }^{33}$. ¿Queremos una declaración europea y de algún modo federal, por encima de las declaraciones de los Estados miembros, un Bill of Rights para toda Europa, o una obligación de mínimos y de resultado y con libertad de elección en los medios, una especie de última medida de seguridad cuando fallan todas las demás? Porque puede que alcanzar ambas finalidades no sea posible.

Tres posiciones doctrinales son posibles en el intenso debate doctrinal que ha habido a la hora de considerar científicamente esta controvertida y débil construcción jurisprudencial:

Estimar que es "una doctrina tan resbaladiza y elusiva como una anguila" 34 -ya que permite rehusar el juicio_-, que se convierte en un sustitutivo de un análisis legal coherente, y en una abdicación de la responsabilidad de la Corte para enjuiciar casos complejos y sensibles en provecho de los alegatos del Gobierno demandado.

Al revés, sostener que es una muestra acertada de autocontención y prudencia judiciales ${ }^{35}$, de respeto al pluralismo de base territorial y a la diversidad

33 Javier GARCÍA ROCA: “El Preámbulo contexto hermenéutico del Convenio: un instrumento constitucional del orden público europeo" en VVAA: La Europa de los derechos: el Convenio Europeo de Derechos Humanos, op. cit., pp. 21-47. Un trabajo que completé en un estudio ulterior «La interpretación constitucional de una declaración internacional, el Convenio Europeo de Derechos Humanos, y bases para una globalización de los derechos" en Revista Iberoamericana de Derecho Procesal Constitucional, núm. 5, 2006, México; y en Revista Europea de Derechos Fundamentales, núm. 6, 2005, pp. 37-82.

34 La expression la usa Lord LESTER OF HERNE HILL: "The European Convention on Human Rights in the new architecture of Europe: general report" en Proceedings of the $8^{\text {th }}$ International Colloquy on the European Convention on Human Rights, Council of Europe, 1995,p. 227.

35 Así se manifiesta un antiguo presidente de la Comisión y de la Corte Sir Humprey WALDOCK: "The efectiveness of the system set up by the European Convention on Human Rights" en 
cultural de las naciones europeas que, por sensatez, debe frenar cierto universalismo en la comprensión de los derechos humanos.

O razonar de forma mucho más matizada y equidistante entre uno y otro polo.

A mi juicio, la cuestión es suficiente compleja como para graduar su valor. El margen de apreciación nacional — se llame cómo se quiera- es necesario por dos razones. Porque refleja una evidente realidad, la tremenda diversidad de los 46 Estados y de los 800 millones de personas - de potenciales justiciables- que habitan desde el Atlántico en Lisboa hasta el Pacífico a la altura de Vladivostok o del mar de Bering, de la costa oeste a la este, y que integran el ámbito territorial y personal de la jurisdicción europea. Y, además, porque responde a la lógica de una protección "internacional" O "supranacional" (dejaré por el momento este debate), en cualquier caso subsidiaria a la interna tanto judicial u ordinaria como constitucional. El TEDH no es un Tribunal Constitucional europeo ni por el arsenal de instrumentos procesales de que goza ni por la naturaleza de su jurisdicción si bien el ejercicio material de sus funciones se aproxima. La solución no es tan sencilla como concluir pidiendo a Estrasburgo que haga siempre un escrutinio menos laxo y más estricto. Deberíamos esforzarnos en construir mejor esta técnica o en sustituirla por otras más depuradas que atiendan al mismo fin y permitan saber con mayor certeza el grado de discrecionalidad que gozan los Estados partes ${ }^{36}$. Esa es mi propuesta. No obstante, insistiré en que - a mi juicio- la verdadera justificación racional de la doctrina radica en la primera razón: la disparidad cultural de las diversas comunidades políticas nacionales; un pluralismo de base territorial sobre el que se asienta una común cultura europea aún de mínimos. Este basamento me parece más sólido que el fundamento derivado del principio de subsidiariedad y de la internacionalidad de la garantía, porque, dada la imprecisión de esa frontera, en la realidad de la jurisprudencia - y tenemos ya una larga experiencia- cuando la Corte quiere hacerlo revisa extremos bastante de detalle de las regulaciones nacionales.

Procesalmente, el margen no supone un "derecho" de los Estados demandados, que no poseen una prerrogativa o privilegio a que se les aplique esta doctrina. No es una especie de "excepción dilatoria", según las viejas leyes procesales civiles, que permitiría al Estado demandado no contestar a la demanda hasta que se resuelva esta cuestión de previo pronunciamiento sobre la falta de jurisdicción o competencia del Tribunal Europeo. El Gobierno de-

Human Rights Law Journal, núm. 1, 1980, p. 1-9, esta doctrina —dice- es la más importante salvaguardia de los poderes soberanos y de la responsabilidad de los gobiernos en democracia.

36 Nestor P. SAGÜES: ob.cit., p. 14 dice que, como técnica de interpretación, la doctrina del margen de apreciación nacional opera fundamentalmente en un cuádruple sentido: a] para $l i$ mitar derechos (por razones lato sensu de orden público o interés general), b] para suspenderlos (desde motivaciones semejantes), c] para permitir la adopción de diversos mecanismos de implementación de los derechos, y d] puede actuar también como justificación de diferentes modos de entendimiento de los mismos. Y cree que es consustancial a ese margen, una verdadera necesidad jurídica, su control por la autoridad supranacional. 
mandado puede esgrimir esa doctrina en su contestación a la demanda, pero es un criterio que libremente la Corte puede acoger - entre otros y no se sabe muy bien cuándo- para decidir el litigio. Si así lo hace, resuelve el litigio por remisión a la solución adoptada por la autoridad nacional. Pero el TEDH no llega ni a declinar su jurisdicción ni siquiera su competencia, simplemente, da por buena una decisión nacional previa. Es, en puridad, una "no decisión" supranacional, o, mejor, una "decisión por reenvio" a la previa e interna. La Corte no dice realmente que la decisión de la autoridad nacional sea correcta, regular, pues a menudo no llega a revisarla. Se hace tácitamente, o a lo sumo expresamente según las sentencias, un juicio liminar de razonabilidad de la decisión nacional, y, sin entrar en un enjuiciamiento del fondo, se deja la cuestión en el ámbito de la resolución de cada Estado. La revisión europea se limita a estimar que lo acaecido en el ordenamiento interno no es manifiestamente irrazonable, pero puede que no sea la mejor solución para optimizar la garantía de los derechos.

El mismo estándar se emplea también a veces en el juicio de amparo constitucional. A menudo el Tribunal Constitucional español, al enjuiciar las lesiones esgrimidas por el actor, decide no revisar las resoluciones judiciales recaídas dándolas igualmente por buenas; y ello se funda igualmente en la lógica de la subsidiariedad. Pero allí el deslinde esta conectado a la competencia de los distintos órdenes de la jurisdicción ordinaria para efectuar un juicio de legalidad, v.gr., la determinación de la cuantía del proceso que justifique el acceso al recurso extraordinario de casación. Sin embargo, aquí, en sede jurisdiccional europea, no existe como criterio de deslinde esa frontera, por imprecisa que resulte, entre legalidad y constitucionalidad, y ahí radica la diferencia y la dificultad de la herramienta que el margen entraña. En un territorio común y sobre una misma materia jurisdiccional, que son los derechos, en ocasiones, el Tribunal Europeo debe rehusar su decisión por su condición de tribunal internacional: un juicio en extremo impreciso y discrecional.

\section{III. ¿PRINCIPIO DE INTEGRACIÓN FUNCIONAL O MARGEN DE APRECIACIÓN NACIONAL?}

Mahorney expresa muy bien este dilema que la doctrina del margen refleja: ¿tenemos una maravillosa riqueza y diversidad de los Estados europeos, o un conjunto de Estados soberanos, envidiosos y culturalmente relativistas ${ }^{37}$ ? Admitido que construimos una Europa de los Estados y no sólo de los ciudadanos y que está dotada de una tremenda diversidad, no obstante, debemos al tiempo avanzar en la integración a través de unos mismos derechos. Esa es la otra cara del problema. Conjugar un intenso pluralismo de base territorial — más que la vieja soberanía absoluta - con una integración europea 
a un tempo prudente que puedan asumir las opiniones públicas de los Estados miembros. ¿Cuándo debemos avanzar en integración o respetar las diferencias nacionales ${ }^{38}$ ?

La jurisprudencia del Tribunal como cualquier otra institución del Consejo de Europa debe servir a este fin. El párrafo $3{ }^{\circ}$ del Preámbulo del Convenio Europeo de Derechos Humanos de 1950 asevera que la finalidad principal del Consejo es realizar una "unión más estrecha entre sus miembros", y que uno de los medios para alcanzar esta finalidad es la "protección y el desarrollo de los derechos humanos y de las libertades fundamentales". Y recordemos que fue escrito en un contexto internacional de guerra fría y de división de Europa en dos bloques que permitía maximizar la perspectiva. Se arranca, en definitiva, de la idea de que los derechos humanos forman parte de la mejor noción de Europa, y parece demandarse una interpretación finalista de las normas reconocedoras de derechos: interpretarlas al servicio de una unión más estrecha. Unos mismos derechos como un medio para una progresiva integración de los europeos.

Previamente el Estatuto del Consejo de Europa de 1949 había ya dicho lo mismo de forma rotunda: que el fin de la institución es crear una organización que lleve a Europa a una asociación más cerrada (preámbulo), y a alcanzar un mayor unidad de sus miembros, salvaguardando ideales y principios que son una herencia común (art. 1); que los principios del Estado de Derecho y el disfrute de los derechos fundamentales por cualquier persona dentro de la jurisdicción de sus Estados miembros son aspiraciones legítimas del Consejo (art. 3); que la seria violación de este art. 3 permite acordar la suspensión de los derechos de representación de un Estado en el Consejo de Ministros (art. 8); etc.

De acuerdo con lo expuesto, ya he razonado en otras ocasiones ${ }^{39}$ que creo que puede hablarse de un principio de integración, en el sentido dinámico y conformador de una comunidad política - ahora europea- al que se refirió Smend cuando acuño de forma clásica, en 1928, el concepto de integración funcional y dinámica ${ }^{40}$. Se trata de alcanzar una unión más estrecha de los Estados miembros —una Europa de los derechos-, protegiendo de modo semejante ciertos derechos básicos de las personas y de las formaciones sociales en que éstas se integran a través de una constante y paulatina - pero matizada y prudente, no voluntarista - jurisprudencia. Una labor promocional

38 Cfr para este dilema Elias KASTANAS: Unité et diversitè: notions autonomes et marge d'appréciation des états dans la jurisprudence de la Cour Européenne des Droits de l' Homme, Établisements Émile Bruylant, Bruselas, 1996, quien se plantea cuándo procede "Respetar la diversidad: una relación de compatibilidad" (parte primera) o "Imponer la uniformidad: una relación de conformidad" (parte segunda).

39 Cfr Javier GARCÍA ROCA: “El Preámbulo contexto hermenéutico del Convenio: un instrumento constitucional del orden público europeo", op. cit.; y "La interpretación constitucional de una declaración internacional, el Convenio Europeo de Derechos Humanos", op. cit..

40 Cfr Rudolf SMEND: Constitución y Derecho Constitucional, Centro de Estudios Constitucionales, Madrid, 1985, original en alemán de 1928. 
o de fomento, y en este sentido integradora, de la jurisprudencia europea: una armonización cultural. Entre otros, Gomes Canoltilho también ha hablado, al ocuparse de los principios de la interpretación constitucional, de un "principio de efecto integrador ${ }^{41}$. Para este autor, se trataría de un principio asociado al más conocido principio de unidad en una de sus formulaciones más simples. En la resolución de los problemas jurídicos constitucionales - y el reconocimiento y la garantía de derechos es materialmente un problema constitucional- deben primarse los puntos de vista que favorezcan una integración política y social.

Algunas de las decisiones que el TEDH adopta manejando distintos criterios hermenéuticos podrían contemplarse perfectamente a la luz de este principio de integración funcional que intento elaborar. Sea como fuere, la Corte no se ha atrevido a denominar así este el principio ni a enunciarlo de forma expresa, aunque en ocasiones maneja la misma lógica lo que justifica mi atrevimiento. Veamos dos ejemplos.

En el Caso Tyrer contra el Reino Unido, de 25 de abril de 1978, cuando el Gobierno demandado adujo que los castigos corporales no repugnaban a la opinión pública británica, la Corte sostuvo que no podía dejar de estar influida por "los desarrollos y estándares comúnmente aceptados en este terreno" según las políticas criminales de los Estados miembros del Consejo de Europa. El argumento redunda en una especie de armonización cultural que propicia una unión más estrecha de los europeos. La práctica tradicional del castigo corporal en las escuelas británicas podía acaso no repugnar a los habitantes de la Isla de Man, pero molestaba por denigrante a la sensibilidad mayoritaria del resto de los europeos.

Más evidente aún es el importante Caso Soering contra el Reino Unido, de 7 de julio de 1989, porque el efecto de la unidad y de la integración funcional se proyecta hacia fuera, y no entre europeos, y entonces el fenómeno se advierte de forma mucho menos polémica. Se discutía la extradición de un acusado por homicidio a Virginia, que aún contempla la pena de muerte. El TEDH razona: que la pena capital no existía en la mayor parte de los Estados signatarios del Convenio Europeo y que en unos pocos ya no se practicaba; que el Protocolo 6 postula su abolición y estaba abierto a la firma desde 1983; y concluye que este "consenso europeo" llevaba a entender que, aunque el Reino Unido no había ratificado ese Protocolo, debía producirse el efecto de que la pena de muerte per se pasara a estar dentro de los tratos prohibidos por el art. $3 \mathrm{CEDH}$.

Sin embargo, la línea mayoritaria de la jurisprudencia en Estrasburgo no se ha apoyado en ese principio de integración funcional, pese a que hemos visto es inmanente al Estatuto del Consejo de Europa y se halla en el preámbu-

41 José Joaquim GOMES CANOLTILHO: Direito Constitucional, Almedina, Coimbra, 1987, p. 162, hay ediciones posteriores. 
lo del CEDH, sino justamente en el contrario, la doctrina del margen de apreciación nacional que no aparece en el Convenio. Por más que medio siglo de jurisprudencia hayan supuesto, sin duda, una aportación decisiva para la erección de un emergente Derecho común en materia de derechos humanos. Pero el Convenio no impone una uniformidad absoluta sino mínima, y, en consecuencia, en líneas generales las medidas restrictivas de los derechos admisibles en un país pueden no serlo en otros. El sistema del Convenio responde a la diversidad europea. El Convenio no es un único código para una inexistente nación europea. El contexto histórico de la actual integración europea no es el mismo que el de la codificación y la emergencia de los Estados nacionales con el liberalismo. Hay que armonizar e integrar de una manera mucho más plural y compleja, respetuosa con las diferencias, y previsiblemente mucho más lenta.

Una última observación, rastrear el uso del margen de apreciación nacional acaba siendo una experimentación sobre el mismo alcance de la jurisdicción de Estrasburgo. Por eso insistiré en que el margen es en todo caso central entre los criterios de decisión de la Corte, pues es raro encontrar una sentencia en la que no se mencione tal cláusula.

\section{EL BANCO DE PRUEBAS DE LA JURISPRUDENCIA. ALGUNOS EJEMPLOS DEL IMPRECISO USO DE ESTA DOCTRINA}

Descendamos a la realidad de los concretos conflictos de derechos que enjuicia el TEDH, para que no parezca que nos ocupamos del sexo de los ángeles... La selección que haré es inevitablemente breve, aleatoria y restringida: una simple muestra ${ }^{42}$. Sería imposible hacerlo con exhaustividad cuando se dictan más de cuatro centenares de sentencias cada trimestre. Si bien son decisiones que he ido reservando con calma a lo largo de la atenta lectura de la jurisprudencia europea, especialmente, de los últimos años. Confío en que valga como muestra. Pretendo sólo evidenciar dos cosas. Primero, el impreciso uso jurisprudencial de la técnica para demostrar que no es una construcción muy conveniente y que sólo puede recibirse como herencia a beneficio de inventario y, en consecuencia, llamar la atención sobre la necesidad de esforzarnos con urgencia en su mejor edificación. Si la doctrina de que me ocupo no tiene una sencilla construcción teórica, tampoco la tiene su aplicación práctica: un observador no sabe con suficiente seguridad jurídica cuando

42 Otras selecciones distintas de jurisprudencia las hacen: Régis de GOUTTES "La théorie de la marge d'appreciation dans la jurisprudence récente de la Cour Européenne des Droits de l'Homme" Revue Trimestrielle des Droits de l'Homme, 1995, núm. 24, pp. 566-614; Howard Charles YOUROV: op. cit.; Diana-Urania GALETTA: op. cit; y Steven GREER: The margin of appreciation: interpretation and discretion under the European Convention on Human Rights, op. cit. 
el TEDH la va usar ni con qué resultados ${ }^{43}$. Y ésta inseguridad no es buena. En segundo lugar, tengo la sensación de que, pese a lo que las sentencias dicen en su motivación, el uso real del margen de apreciación nacional, sus consecuencias, tienden a menguar en los últimos años, pese a que se mantiene su invocación en la fundamentación de las sentencias. La Corte se inclina a no sentirse limitada por esta restricción siempre que lo desea. Al cabo no deja de ser una limitación autoimpuesta. Como cualquier Tribunal final -otro tanto hacen sus homónimos los Tribunales Constitucionales- el TEDH se dirige, consciente o inconscientemente, a acrecentar la intensidad de su jurisdicción revisora. Por eso decía antes que su condición de órgano jurisdiccional final y su poder de revisión limitado están en cierta insoslayable tensión. Y, en líneas generales, no me parece una mala solución siempre que no se incurra en excesos.

Seleccionaré algunos casos que nos permitan razonar al hilo de los mismos.

a] Derecho a la vida (art. 2) y tratos prohibidos por el Convenio (art. 3): la tortura y otros tratos inbumanos y degradantes. Aquí no suele dejarse margen nacional alguno y la revisión es intensa, puesto que se trata de derechos que la Corte considera "absolutos". Incluso en supuestos de terrorismo, muy sensibles a las apreciaciones y realidades nacionales, así en el Caso Ramírez Sánchez contra Francia, de 27 de enero de 2005, por ejemplo, al apreciarse las condiciones objetivas de la detención de un peligroso terrorista y la forma de cumplimiento de la pena (hubo un completo aislamiento sensorial y social durante ocho años), se revisaron estos extremos y se estimó la violación que la víctima denunciaba.

Igualmente, respecto del serio problema de la situación de los presos y el penoso estado de las cárceles en muchos países del Este. Ente otros, un precedente es el Caso Kalashnikov contra Rusia, de 15 de julio de 2002. Una sentencia repetida en muchos otros litigios y contra varios países según la cual las deficientes condiciones objetivas y estructurales de cumplimiento de las penas en las cárceles pueden constituir un trato prohibido por el Convenio. La posición de la Corte coincide con el Informe emanado por el Comisionado para los derechos humanos del Consejo de Europa, Sr. Gil Robles, sobre el estado de los derechos en Rusia tras su visita en el 2004. Bastantes Estados han sido condenados por idénticas razones.

Y otro tanto podría explicarse con las violaciones de los derechos de la minoría kurda en Turquía que han dado lugar a un elevado número de sentencias de condena y pusieron en marcha una política del Consejo de Europa de tolerancia cero de ciertas prácticas.

La solución es correcta. Unas bases imprescindibles para cualquier integración europea están en respetar aquellos derechos más indisociablemente ligados a la dignidad humana. No matar ni torturar y respetar las garantías convencionales de procedimiento, incluso para luchar contra el terrorismo y

43 Las críticas doctrinales por la subjetividad que introduce esta doctrina en la interpretación del Convenio son muy mayoritarias p. ej. Oren GROSS \& Fionnuala Ní ALOÁIN: op. cit., p. 629. 
otras lacras que son una grave amenaza para nuestras comunidades políticas, es un principio ilustrado irrenunciable de la cultura europea. Y en esto la Europa de los derechos se diferencia a veces de los Estados Unidos ${ }^{44}$.

b] Derecho a un Tribunal independiente e imparcial (art. 6). La Corte ha comenzado a usar aquí un "enfoque pragmático" a partir del Caso Hauschidlt contra Dinamarca, de 24 de mayo 1989, generando una gran inseguridad, al afirmar que "la respuesta de si existe parcialidad o no o no varía según las circunstancias de cada causa", ya no es suficiente que un juez haya acumulado funciones instructoras y juzgadoras sino que habrá de determinarse caso a caso. Antes podía saberse cuando se violaba el derecho en ese aspecto, ahora ya no, y el margen de apreciación nacional en consecuencia ha crecido. No obstante, me parece que un verdadero Tribunal obligado a hacer una interpretación constitucional de una declaración de derechos europea debe mantener verdaderos estándares generales para no generar confusión.

c] Derecho a la vida privada y familiar (art. 8). Se han revisado muchos extremos y contenidos hasta edificar una cláusula general y horizontal de contenidos muy amplios, identificados jurisprudencialmente mediante una interpretación constructiva y de objeto impreciso v.gr. los derechos de visita a los hijos entre miembros de uniones de hecho, o las regulaciones que dificultan la investigación de la paternidad. Así en el Caso Shofman contra Rusia, de 24 de noviembre de 2005, la Corte constató la diversidad de sistemas de investigación de la paternidad, y señaló que no hay un estándar europeo tanto en el tiempo fijado para ejercer la acción como en el cómputo, y aseveró que no le correspondía sustituir a los Estados en su regulación, pero este cierto margen de apreciación nacional — se dijo- no es compatible con presunciones legales que impidan que prevalezcan las realidades sociales y biológicas. De nuevo en Ebru y Tayfun Engin Colak contra Turquía, de 30 de mayo de 2006, se reconoce ese margen y se admite que es compatible con el Convenio que los Estados no prevean medios de obligar a los supuestos padres naturales demandados a someterse a pruebas de ADN, pero asimismo se dice que deben ordenar un justo equilibrio de intereses con los derechos de quienes ejercen la acción de filiación, y extraer consecuencias del rechazo y de otras pruebas sin mantener a los actores en una prolongada situación de incertidumbre. El margen nacional existe, pero no es ilimitado ni irrevisable.

d] Libertad religiosa (art. 9). En el Caso Leyla Sahin contra Turquía, de 10 de noviembre de 2005, la Corte Europea confirmó la decisión del Tribunal Constitucional turco que sostuvo la prohibición del velo islámico y otros atuendos religiosos en las universidades. A la actora no le dejaron examinarse en la facultad de Medicina ni luego matricularse por esta causa. El TEDH fundó su decisión, poco razonada, en la doctrina del margen, lo cual le llevó

44 Si bien oportunas sentencias de la Supreme Court de los Estados Unidos nos hacen recuperar en parte la confianza en una cierta globalización en la cultura de los derechos. Me refiero a Hamdam v. Rumsfeld, de 29 de junio de 2006, sobre los juicios en Guantánamo por comisiones militares excepcionales a personas implicadas en los atentados del 11 de septiembre de 2001. 
a admitir que la reglamentación de la vestimenta en la Universidad de Estambul era una medida necesaria. Creo — como se ha afirmado- que es «una apuesta equivocada " ${ }^{45}$. Yo hubiera dicho justamente lo contrario. Pero, en cualquier caso, sea cual fuere el fallo, debió motivarse de una manera más argumentada; y, en sentido opuesto, no podemos olvidar el fuerte debate cultural a la luz de los principios republicanos que esta cuestión del velo ha provocado en Francia, o las dificultades para mantener el laicismo como signo de identidad de la República turca desde sus orígenes.

e] Limites a las manifestaciones de la libertad de asociación (art. 11). Se ha revisado intensamente la disolución de partidos políticos dejando un escaso margen de apreciación nacional. En el Caso del Partido Comunista Unificado de Turquía, de 30 de enero de 1998, la Corte dice que, respecto de la disolución de los partidos políticos, "los Estados contratantes no disponen más que de un margen de apreciación nacional reducido" y que es necesario un control europeo riguroso. La democracia es un elemento del orden público europeo y las libertades de asociación y de expresión en su ejercicio colectivo a través de los partidos son indefectibles para que ese régimen exista.

Incluso, también, aunque los idearios que esos partidos defiendan sean especialmente chocantes para la sensibilidad nacional como ocurre, en los nuevos Estados democráticos que huyen del totalitarismo, con los viejos partidos comunistas de algún modo herederos de los partidos de Estado. En el Caso Partido Comunista (NEPECERESTI) y Ungureanu contra Rumanía, de 3 de febrero de 2005, se denegó por la Administración y los Tribunales rumanos el registro de este partido por querer instaurar un Estado fundado sobre una doctrina comunista y la dictadura del proletariado. La Corte Europea estima violada la garantía del derecho de asociación y subraya que nada autoriza a pensar que ese partido "apele a la violencia" y a destruir los derechos y, con sentido cabal, resalta que ya existen otros partidos comunistas en Europa. Claro está que es diferente cuando el ideario o programa del partido podrían incitar al odio religioso entre comunidades como se estimó ocurría en el mencionado Caso del Partido de la Prosperidad en Turquía.

Respecto de la libertad sindical, el Caso Tüm Haber Sen y Çmar contra Turquía, de 21 de febrero de 2006, analiza una prohibición de que los trabajadores contratados por la República turca en los servicios de comunicaciones puedan fundar sindicatos. El Gobierno demandado aduce que la Constitución y las leyes nacionales no permiten fundar sindicatos a los funcionarios. La Corte estima la violación y razona que el art. $11 \mathrm{CEDH}$ reconoce a toda persona el derecho a asociarse para la defensa de sus intereses sin excepciones; ciertamente, el apartado $2 .^{\circ}$ permite establecer "restricciones" — que no es lo mismo que "exclusiones» - para las Fuerzas Armadas, la Policía y la

45 Así se manifiestan Eugenia RELAÑO y Alain GREY: "Leyla Sahin contra Turquía y el velo islámico: la apuesta equivocada del TEDH.. Sentencia de 10 de noviembre de 2005 en Revista Europea de Derechos Fundamentales, núm. 6, 2006, p. 213-238, epígrafe "La doctrina del margen de apreciación y el concepto de laicidad. 
Administración del Estado. Pero estas limitaciones deben interpretarse de forma estricta, teniendo los Estados — se dice- un margen de apreciación nacional reducido.

En cambio, mucho antes se admitió que la libertad sindical en su vertiente negativa, la libertad de no asociarse, es compatible con muy variados sistemas de relaciones industriales, que son reflejo de la variedad de tradiciones nacionales, singularmente, la británica. De nuevo, un "enfoque pragmático" (pragmatic approach) del TEDH. Así en el Caso Young y otros contra el Reino Unido, de 13 de agosto de 1981, una empresa pública que había llegado a un acuerdo con tres sindicatos mayoritarios por el cual se supeditaba el acceso a la empresa y la permanencia en el empleo a la afiliación a uno de ellos. El Tribunal evitó enjuiciar en abstracto el sistema, pero estimó el despido por estos motivos lesivo del Convenio, al existir una ingerencia innecesaria en el derecho. Se ha criticado la sentencia como un ejercicio de funanbulismo.

f] Derecho a contraer matrimonio (art. 12). La Corte no se atrevió en los años ochenta a reconocer el derecho al divorcio en países en los que no estaba admitido. Se aplicó la doctrina del margen en el Caso Johnston contra Irlanda, de 18 de diciembre de 1986, diciéndose que el art. 12 CEDH incluye las relaciones maritales, pero no su disolución. Obsérvese que no es muy lógico que el derecho de asociación tenga una vertiente positiva junto a otra negativa, y no el derecho a contraer matrimonio que es igualmente un derecho de libertad. Pero es una sentencia de 1986 y en ese momento Irlanda tenía un artículo en su Constitución (art. 41.3) que impedía en todo caso a la ley acordar la disolución del matrimonio, luego se matizó en una reforma. ¿Qué haría ahora la Corte 20 años después tras la intensa evolución social sobrevenida?

Valga como indicio que, de forma algo contradictoria, porque pugna aún más con algunas conciencias religiosas, el TEDH ha reconocido después el derecho a contraer matrimonio de los transexuales. Una libertad muy controvertida para la opinión pública de muchos países de Europa de mayoría católica. Para ello la Corte abrogó su anterior orientación jurisprudencial (media docena de sentencias desde 1980: Casos Van Oosterwijck, Rees, Cossey, Sheffield y Horskam, B. contra Francia, e X,Y y Z contra el Reino Unido) dándose un giro de $180^{\circ}$. Un buen ejemplo de interpretación evolutiva y de acuerdo con la realidad social del momento. En efecto, en los Casos Goodwin e I. contra el Reino Unido, ambos de 11 de julio de 2002, se afirma que la inhabilidad de una pareja para concebir o engendrar un niño no puede ser vista como algo que elimine el derecho a disfrutar del derecho a contraer matrimonio. Y se dice que deben tenerse en cuenta los importantes cambios operados en el terreno de la medicina y de la ciencia (había un informe de la Comisión), al tiempo que la Corte se apoya en el reconocimiento más amplio de la Carta de Derechos Fundamentales de la Unión Europea de 2000.

¿Con arreglo a qué criterios el TEDH decide aplicar la doctrina del margen nacional en casos de divorcio, y, en el matrimonio de los transexuales, primero sí, y luego no? ¿Se trata sólo del transcurso del tiempo que produce el cambio de la realidad social? 
g] Protección de la propiedad (art. 1 P1). En esta garantía del Protocolo 1. ${ }^{\circ}$ se reconoce que toda persona física o jurídica tiene derecho al respeto de sus bienes en las condiciones previstas por las leyes. Un derecho que tuvo un conflictivo reconocimiento por parte de algunos Estados miembros y por eso acabo exiliado en el protocolo adicional. ¿Pueden revisarse esas condiciones generales reguladas en las leyes nacionales? La pregunta suele responderse por el TEDH reconociendo que tales condiciones legales dan lugar a un amplio margen, lo que limita en teoría el juicio de proporcionalidad. La jurisprudencia ha interpretado que el artículo comprende tres reglas. La primera consiste en el derecho al respeto o goce pacífico de los bienes de las personas. La segunda es una garantía frente a privaciones ilegítimas: sólo puede expropiarse o privarse de la propiedad en casos de utilidad pública y con las condiciones previstas por la Ley. La tercera es la posibilidad de que los Estado establezcan restricciones "de acuerdo con el interés general". En principio, el TEDH ha reconocido que las autoridades nacionales están mejor situadas que el juez internacional para apreciar cuál es ese "interés general" de una comunidad. Pero una sistematización de la jurisprudencia desde esta óptica es harto complicada.

En el Caso Kjartan Asmundsson contra Islandia, de 12 de octubre de 2004, la Corte reconoce primero el amplio margen del que gozan los Estados en el área de la legislación social pero, a continuación, estima desproporcionado y entiende que lesiona la garantía europea (art. 1 P1, regla primera) que el actor, que hizo unas contribuciones a un fondo de pensiones y contrajo una discapacidad laboral, se viera privado totalmente y de forma sobrevenida de su derecho a pensión en virtud de los cambios de criterios legales. ¿Es esta intensa revisión adecuada a un margen de apreciación nacional que se estima amplio?

El Caso Back contra Finlandia, de 20 de julio de 2004, analizó la regla segunda. La noción de utilidad pública a efectos de expropiación implica el examen de cuestiones políticas, económicas y sociales. El legislador posee una gran latitud para mantener políticas y la Corte debe respetarlas "salvo si el juicio se revela manifiestamente desprovisto de bases racionales". Un buen estándar que debemos reservar. Allí donde parece existir un margen de apreciación nacional no se debería revisar si el fin o la medida son legítimas salvo cuando uno u otra sean manifiestamente irracionales. Pero eso ocurre con más frecuencia de lo que parece a la hora de hacer concretas ponderaciones. Así en el Caso Kliafas y otros contra Grecia, de 8 de julio de 2004, se insistió también en que la noción de utilidad pública era amplia por naturaleza y en que la Corte "debe respetar la manera en que (...el legislador) concibe los imperativos de utilidad pública salvo si su juicio se revela manifiestamente desprovisto de base razonable. Y se admitió que las autoridades nacionales están en mejor posición que el juez internacional para determinar que es de utilidad pública. Sin embargo y dicho todo esto, se acaba por estimar violado el derecho puesto que no existía un equilibrio entre el interés general y el individual de los recurrentes, unos funcionarios y expertos contables a los que, al liberalizarse esta profesión y reorganizarse el cuerpo y continuar efectuando 
su labor, se les obligó a rembolsar al Estado unos ingresos de dinero que habían percibido durante el período transitorio y que eran fruto de su trabajo, una medida que el TEDH enjuició desproporcionada.

Igualmente de los Casos Allan Jacobsson contra Suecia, de 25 de octubre de 1989, y Fredin contra Suecia, de 18 de febrero de 1991, entre otros muchos, se desprende que el TEDH dice autolimitarse en el examen de si la regulación de la propiedad y sus restricciones (regla tercera del art. 1 P1) son adecuadas al Convenio, admitiendo un teórico amplio margen de apreciación nacional. Pero no es extraña en la jurisprudencia la realización de escrutinios más o menos intensos.

h] Derecho de instrucción (art. 2 P1). Pese a que el Consejo de Europa hizo un reconocimiento de mínimos de este derecho y no se garantizan todos los amplios derechos educativos, se han revisado p. ej. los concretos requisitos para acceder a la enseñanza. En el Caso Múrsen Eren contra Turquía, de 7 de febrero de 2006, el actor no pudo acceder a la enseñanza universitaria de su elección porque, aunque pasó un complejo examen hecho por ordenador, las autoridades académicas anularon los resultados de la prueba al presumir o sospechar que había copiado, dado el elevado número de respuestas acertadas. La Corte entiende violado el derecho y entra a revisar la discrecionalidad de la medida adoptada por las autoridades académicas ya que no estaba prevista en las leyes. El Magistrado disidente turco invocó — sin éxito- el margen de apreciación nacional de los hechos por parte de las autoridades administrativas y judiciales internas, señalando que la Corte no debió interferir ese juicio. En efecto, me parece que si el TEDH se tomara en serio esa doctrina, como una verdadera regla de autocontención, no debería haber entrado a revisar los hechos del supuesto. Pero lo hace y creo que es justo y correcto, porque se revisa una decisión arbitraria al no estar predeterminada y prevista en las leyes. Lo que inclina a pensar que un verdadero parámetro jurídico de decisión no puede ser tan variable.

i] Derecho de sufragio en elecciones libres (art. 3 P1). El margen de apreciación nacional suele ser aquí reducido, en cuanto se trata de un derecho democrático y la democracia es un elemento del orden público europeo, pero hay también excepciones.

En el Caso Hirst contra Reino Unido, de 30 de marzo de 2004, se revisa intensamente el derecho al sufragio activo de los presos, la falta de capacidad electoral de los condenados por sentencias penales, y se estima que se ha violado el derecho pese a reconocerse que hay un amplio margen de apreciación nacional. De nuevo el margen se respeta en teoría pero no en la realidad. Se acude a un pormenorizado examen de Derecho comparado y se concluye que 18 Estados no imponen a los prisioneros restricciones al voto, y otros 13, en cambio, lo prohíben y, entre uno y otro polo, los demás Estados imponen la privación del mismo según el tipo de ofensa como parece razonable. El TEDH afirma que la doctrina del margen no justifica restricciones que son «incuestionadas y pasivas adherencias a la tradición histórica». Y se razona que asociar moralidad con Código Penal y privar del sufragio activo a 
cualesquiera condenados es un atavismo. Votar es un instrumento de socialización, de inclusión social, coadyuva a no incrementar la exclusión del preso dentro de una comunidad. Esta buena decisión europea parece influida por la Corte Suprema de Canada en el Caso Sauvé contra el Fiscal General, de 31 de octubre de 2002, que allí mismo se cita. Un buen ejemplo de globalización en la garantía de los derechos.

En el Caso Py contra Francia, de 15 de diciembre de 2000, se revisan las elecciones y el derecho de sufragio activo al Parlamento de Nueva Caledonia, territorio francés en el que, a esos efectos, se reclama el deber de residencia, y la Corte reconoce que los Estados gozan de un amplio margen de apreciación nacional en materia electoral sin discutir este extremo de la regulación. Recuérdese que precisamente el art. 3 P1 se relegó al Protocolo Adicional, porque algunos Estados no querían que se les impusiera limitaciones a su soberanía: ni la proporcionalidad ni ningún otro sistema electoral.

Curiosamente, la solución contraria - no respetar el margen- se adopta en el Caso Melnychenko contra Ucrania, de 19 de octubre de 2004. La Corte analiza la legislación electoral que no se contentaba con la residencia legal y exigía una residencia "habitual" y "continuada" en el territorio de Ucrania, para poder registrase administrativamente e inscribirse en un censo especial. Una circunstancia que actuaba como condición de elegibilidad. La Corte Europa desciende a la realidad social ucraniana de ese momento: el miedo a la persecución política bajo la dictadura, la difícil situación de los candidatos asumiendo graves riesgos para su integridad física (un candidato a presidente fue envenenado), circunstancias que probablemente les obligaban a dejar el país para poder ejercer sus derechos políticos. Y, en consecuencia, resuelve estimar violada la garantía por la exigencia legal de este requisito.

Uno y otro caso sobre el alcance del deber de residencia son semejantes pero cambian los supuestos de hecho, la realidad social de Francia no era igual que la de Ucrania en esos momentos: el derecho vivido, o derecho en acción. Y con mayor razón respecto de los derechos humanos que son un case-law donde los hechos se mezclan de manera inextricable con las normas internacionales reconocedoras de derechos. Es cabal pensar que podía caber un margen de apreciación nacional en el primer caso, pero no en el segundo.

j] Como conclusión, tras seguir un método inductivo en torno a estos ejemplos seleccionados, la revisión jurisprudencial produce una clara sensación de inseguridad jurídica y pone de manifiesto un exceso de discrecionalidad en la decisión.

\section{RECAPITULACIÓN}

La doctrina del "margen de apreciación nacional" vale para casi todo: para una cosa y su contraria. Incluso, se mantiene como motivación de algunas sentencias, pero conduce al resultado opuesto del que debería ser el lógico: un control europeo menos intenso en virtud del mayor margen nacional 
en la decisión que el Tribunal dice reconocer. Parece ser más una justificación, y ocasionalmente una cláusula de estilo, que un criterio de interpretación. Creo, pues, que no estamos ante una verdadera "doctrina", pese a que así se la denomine habitualmente: ni en el sentido de una ciencia común que profesan la mayor parte de los autores, los miembros de la "doctrina científica"; ni como "doctrina legal" en cuanto opinión ordenada que se deduce de la jurisprudencia. Tampoco creo valga como una enseñanza que la Corte imparta para instruir tanto a los Estados partes sometidos a su jurisdicción, de forma que sepan a qué atenerse respecto del grado de discrecionalidad del que gozan, como a los recurrentes, de manera que puedan prever la intensidad de la revisión europea que deben esperar. Es, en suma, una cláusula demasiado imprecisa y discrecional, un criterio de decisión no reglado y de aplicación irregular, inidóneo en buena medida para cumplir cualquiera de estos fines. Una fórmula a la que libremente acude la jurisprudencia y que resulta de vaga sistematización científica. Dista de ser una verdadera teoría jurídica. Pero curiosamente es difícil saber si no está provista de equidad.

En efecto, la Corte Europea ejerce un discrecionalidad judicial en la que no se percibe con seguridad el motivo por el cual ha de respetar la solución nacional sobre la imparcialidad de un tribunal, la investigación de la paternidad, el velo religioso, el divorcio, la sindicación, la utilidad pública de una expropiación o la configuración legal del sufragio, pero no en otros casos, no menos controvertidos, como el matrimonio de los transexuales o las limitaciones a la expulsión de los extranjeros. Tal vez la respuesta haya que buscarla no en abstracto sino en el fondo de cada caso concreto (en una ponderación de las circunstancias políticas e históricas de cada país, el grado de asentamiento del Estado de Derecho, además de la naturaleza del derecho y de la lesión que la víctima aduce). Al cabo lo que sea un derecho no puede juzgarse en abstracto, omitiendo los marcos culturales y económicos que lo circundan ${ }^{46}$. Acaso subyace el prudente propósito del TEDH, cuando aplica el margen de apreciación nacional, de no crear problemas mayores - que podrían producirse de decidir el pleito-, porque la solución interna no se le antoja plenamente insatisfactoria. Por eso estamos ante una incierta doctrina.

Aunque pueda parecer contradictorio con los razonamientos doctrinales expuestos, estimo que es bastante cabal la posición a la que el margen de apreciación nacional a menudo responde: una actitud judicial de deferencia hacia las autoridades internas, al estar ubicadas en una mejor sede para el enjuiciamiento de ciertos conflictos de intereses y responder democráticamente ante sus electorados. Pero no puede ocultarse su débil construcción jurisprudencial y las inseguridades que ocasiona.

La fórmula responde muchas veces — la verdad es que no siempre- a realidades tozudas e inaplazables: a la subsidiariedad inherente a una protec-

46 Así nos lo recuerda con frase feliz Nestor P. SAGÜES: op. cit., p. 15. El mundo de los derechos es inevitablemente un case-law. 
ción supranacional, y, sobre todo, al pluralismo de base territorial que diferencia unas comunidades políticas nacionales con realidades todavía muy diversas. El juicio de convencionalidad en la garantía de los derechos no puede hacerse de forma realista apartándose de estas variables desde un activismo que ignore la Historia de Europa y la diversidad de sus Estados y ordenamientos. Es un problema de equilibrio.

Sin embargo, deberíamos resolver convencionalmente en qué ocasiones el TEDH debe autocontenerse y en cuáles, por el contrario, puede armonizar un entendimiento cultural común de los derechos de los europeos y avanzar sin temor en su integración. Ésta es la finalidad propia del Consejo de Europa al que el Tribunal sirve. Y la misma lógica de la universalidad de los derechos, pese a sus condicionamientos materiales, que impide entendimientos harto desiguales. Por consiguiente, es razonable pensar que el margen debería ser normalmente mínimo, necesitado de una justificación expresa, y centrado en algunos derechos de intensa configuración legal. Pero no universal o para todos los derechos ni, menos aún, máximo. Y, desde luego, debería estar fundado en las distintas realidades sociales y culturales, y no en obstáculos fácticos que redunden en inadmisibles violaciones de derechos, consagrando ulteriores indefensiones cual si fuera una patente de corso para los Estados soberanos. La tutela de los derechos humanos no es ya un huerto cerrado en manos de la soberanía estatal.

Quizá la prudencia inherente a cualquier iuris prudentia aconseje alcanzar a veces los mismos resultados, pero espero que en el futuro mediante el empleo de técnicas jurídicamente más precisas o tras una mejor construcción y depuración de la llamada doctrina del margen. Éste es un reto que deberíamos afrontar tanto la propia Corte Europea como la doctrina científica de ambos hemisferios.

ABSTRACT. The established case-law of European Court of Human Rights on margin of national appretiation is one of the capital criteria for reviewing the decision made by national authorities after a superficial examination of the facts. Its application is very imprecise and discretionary, producing sometimes unpredictable, astonishing even contradictory effects. It corresponds more to the justice of case than a genuine general legal doctrine. Its current ground should be more in the considerable cultural pluralism of the peoples that take part of the Council of Europe than in the national (state) sovereignty, in view of the context of European integration, because the realities of the suppositions of fact should be integrated in the rights. But the Court itself and the scientific academic doctrine should make an effort in substituting this tool for other more accurate legal technique that may fulfil similar aims. 